\title{
Protection of Steel Rebar in Salt-Contaminated Cement Mortar Using Epoxy Nanocomposite Coatings
}

\author{
The Huu Nguyen ${ }^{1}$ and Tuan Anh Nguyen $\mathbb{D}^{2}$ \\ ${ }^{1}$ Faculty of Chemical Technology, Hanoi University of Industry, Bac Tu Liem, Hanoi, Vietnam \\ ${ }^{2}$ Institute for Tropical Technology, 18 Hoang Quoc Viet, Cau Giay, Hanoi, Vietnam \\ Correspondence should be addressed to Tuan Anh Nguyen; ntanh@itt.vast.vn
}

Received 14 December 2017; Revised 13 March 2018; Accepted 20 March 2018; Published 24 April 2018

Academic Editor: Adalgisa Rodrigues de Andrade

Copyright (c) 2018 The Huu Nguyen and Tuan Anh Nguyen. This is an open access article distributed under the Creative Commons Attribution License, which permits unrestricted use, distribution, and reproduction in any medium, provided the original work is properly cited.

\begin{abstract}
Epoxy reinforced with two kinds of nanoparticles dealing with nano- $\mathrm{SiO}_{2}$ and nano- $\mathrm{Fe}_{2} \mathrm{O}_{3}$ was coated on steel rebar embedded in a chloride contaminated cement mortar. $\mathrm{NaCl}$ was added to the fresh Portland cement paste (at $0.3 \%$ and $0.5 \%$ by weight of cement) to simulate the chloride contamination at the critical level. The effect of incorporating nanoparticles on the corrosion resistance of epoxy-coated steel rebar was investigated by linear potentiodynamic polarization and electrochemical impedance spectroscopy. For the $0.3 \mathrm{wt}$.\% chloride mortars, the electrochemical monitoring of the coated steel rebars during immersion for 56 days in $0.1 \mathrm{M}$ $\mathrm{NaOH}$ solutions suggested the beneficial role of nano- $\mathrm{Fe}_{2} \mathrm{O}_{3}$ particles in significantly improving the corrosion resistance of the epoxy-coated rebar. After 56 days of immersion, the nano- $\mathrm{Fe}_{2} \mathrm{O}_{3}$ reduced the corrosion current of epoxy-coated rebar by a factor of 7.9. When the chloride concentration in the cement mortar was $0.5 \mathrm{wt} . \%$, the incorporation of nanoparticles into the epoxy matrix did not enhance the corrosion resistance of epoxy coating for the rebar. At this critical level, chloride ions initiated rebar corrosion through nanoparticles at the epoxy/rebar interface.
\end{abstract}

\section{Introduction}

The corrosion of reinforced rebar in concrete structures has been a serious problem worldwide. In general, the steel rebar embedded in concrete can be well protected chemically and physically by a concrete cover. Cement hydration leads to the highly alkaline $(\mathrm{pH}>13)$ pore solution of concrete, which promotes the formation of a passive layer (an oxide/hydroxide film) at the steel surface, and thus the corrosion rate is negligible. On the other hand, the concrete cover could also prevent the ingress of aggressive substances into the surface of the rebar. In the ideal condition, the reinforced concrete structures remain stable for a very long time ( 100 years). However, in reality, their lifespan is shorter by about $30-50$ years than expected.

The passive layer on the rebar surface in concrete could be destroyed by two phenomena: (i) carbonation and (ii) ingress of chloride ions. The ingress of atmospheric carbon dioxide into the concrete (carbonation) reduces the $\mathrm{pH}$ value of the pore solution (to the range of 8 to 9) [1], whereas the chloride, often originating from marine environments or deicing applications, can initiate rebar corrosion once its concentration reaches a threshold level [2]. Under normal circumstances, the threshold chloride content typically varies from 0.2 to 0.5 per cent by weight of cement $[3,4]$.

Epoxy coating has been applied to protect the steel reinforcement in concrete structures [5-7]. However, its application is rather limited due to its susceptibility to damage by surface abrasion and wear $[8,9]$. Epoxy coating also has low resistance to the initiation and propagation of cracks [10]. It was reported that the incorporation of nanoparticles into epoxy resins could enhance the integrity and durability of coatings, since the nanofillers dispersed in coatings could fill cavities [11-13], causing crack bridging, crack deflection, and crack bowing [14]. Other authors also signaled that the incorporation of nanoparticles into epoxy resins significantly improved their barrier properties for anticorrosion [1518] and inhibited their trend to blister or delaminate [19]. 
Recently, we reported that the presence of nanoparticles in an epoxy coating showed an 11-910-fold significantly reduced corrosion rate of epoxy-coated steel in $3 \mathrm{wt} . \% \mathrm{NaCl}$ solution, with the nano- $\mathrm{Fe}_{2} \mathrm{O}_{3}$ being the most effective [20].

The present study was designed to apply the epoxy nanocomposite coating to protect the steel rebar in concrete structures under chloride contaminated conditions. Two kinds of nanoparticles (nano- $\mathrm{SiO}_{2}$ and nano- $\mathrm{Fe}_{2} \mathrm{O}_{3}$ ) were used to investigate their efficacy on corrosion protection. $\mathrm{NaCl}$ was added to a fresh Portland cement paste (at $0.3 \%$ and $0.5 \%$ by weight of cement) to simulate the chloride contamination at the critical level. The effect of nanoparticles on the protective performance of epoxy coating for steel rebar was evaluated using the electrochemical measurements.

\section{Materials and Methods}

2.1. Materials. The cement mortars used ASTM Type I Portland Cement (Vietnam Portland PC30). The fine aggregate used was river sand sieved to allow a maximum aggregate size of $2 \mathrm{~mm}$ before proportioning and admixing.

The epoxy resin and its hardener used in this research were obtained from Phoenix Resins Inc. (Cinnaminson, NJ, USA), commercially known as MAS Epoxies-FLAG ${ }^{\mathrm{TM}}$. The liquid epoxy resin was a blend of multifunctional low-molecular-weight diluents and the di-glycedal ether of bisphenol-A, and the hardener was based on adduction reaction chemistry of aliphatic amines. The weight ratio of the epoxy resin to the hardener was $2: 1$. Nano- $\mathrm{SiO}_{2}$ and nano$\mathrm{Fe}_{2} \mathrm{O}_{3}$ particles, obtained from Sigma-Aldrich (Singapore), had a mean diameter of 15 and $25 \mathrm{~nm}$ and a specific surface area of $590-690$ and $50-245 \mathrm{~m}^{2} / \mathrm{g}$, respectively. The steel rebars purchased from Vietnam Hoa-Phat Steel Co. Ltd., were a low carbon steel wire rod (diameter of $0.6 \mathrm{~cm}$, JIS G35051996, SWRM6), with the chemical composition C $(\leq 0.08 \%)$, $\mathrm{Mn}(\leq 0.6 \%), \mathrm{P}(\leq 0.045 \%)$, and S $(\leq 0.045 \%)$.

2.2. Epoxy Nanocomposite Coating Preparation. Steel rebar was polished on silicon carbide $(\mathrm{SiC})$ papers down to a grid size of 1000. After polishing, the sample surface was rinsed with tap water, sonicated in ethanol, and then rinsed with ethanol. In this study, epoxy nanocomposites are prepared by dispersing nanoparticles into the epoxy matrix with acetone as solvent and with the aid of sonication [20]. Before mixing, both the resin and its hardener were diluted separately by acetone with a $1: 1$ weight ratio. Nanoparticles, which account for 1 wt. $\%$ of the total weight of resin and hardener, were added to the resin-acetone solution, followed by stirring and sonication (Model TPC-15H, Telsonic AG, Switzerland) for $15 \mathrm{~min}$. After that, the hardener-acetone solution was added to the mixture, followed again by stirring and sonication for $15 \mathrm{~min}$. The steel rebar was dipped once into the final mixture and then kept in a dry place at room temperature for 7 days to allow full curing, which led to the formation of a uniform coating for the corrosion resistance test.

The average thickness of as-prepared coatings on steel substrate was $40 \pm 2 \mu \mathrm{m}$ [21]. The as-prepared coating adhesion on steel substrate was evaluated using the PosiTest Pull-Off Adhesion Tester. The values of adhesion strength

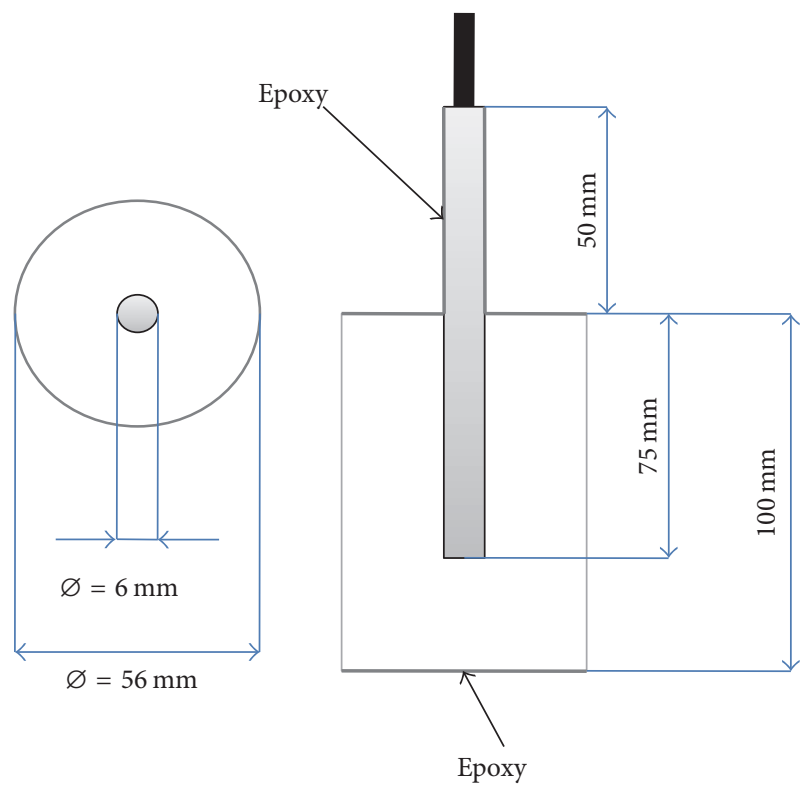

FIGURE 1: Diagram of the steel reinforced mortar samples: cover thickness $=2.5 \mathrm{~cm}$, steel bar diameter $=0.6 \mathrm{~cm}$, and surface area of the electrode $=12.25 \mathrm{~cm}^{2}$.

for plain epoxy, epoxy/nano- $\mathrm{Fe}_{2} \mathrm{O}_{3}$, and epoxy/nano- $\mathrm{SiO}_{2}$ were $4.04 \pm 0.51 \mathrm{MPa}, 4.29 \pm 1.11 \mathrm{MPa}$, and $3.58 \pm 0.16 \mathrm{MPa}$, respectively, as described in a previous publication [21].

\subsection{Electrochemical Characterization of Rebar in Cement} Mortar. For the electrochemical test, steel rebars (with or without coatings) were embedded in each salt-contaminated cement mortar, with a mortar cover of $2.5 \mathrm{~cm}$ (Figure 1). For each sample, the ratio of "cement : sand : water : chloride" by weight was " $1: 1.75: 0.45: 0.003$ and 0.005 ." After mixing, the fresh mixture was poured into the polypropylene plastic molds to form $\Phi 100 \mathrm{~mm} \times 50 \mathrm{~mm}$ cylindrical samples. The steel reinforced cement mortar specimens were demolded after $24 \mathrm{~h}$ and then cured in a wet chamber (relative humidity in excess of $95 \%$, temperature of $25^{\circ} \mathrm{C}$ ) for 28 days, before being subjected to the electrochemical tests.

Electrochemical measurements were conducted using a three-electrode system. The epoxy-coated steel rebar in cement mortar served as the working electrode, while the counter electrode and the reference electrode used were a platinum electrode and a saturated calomel electrode (SCE), respectively.

To resolve the effect of salt contamination on corrosion of epoxy-coated rebar, the solutions tested were $0.1 \mathrm{M} \mathrm{NaOH}$ solutions, which ensured that the surrounding highly alkaline medium was the pore solution of mortar. Two methods were used to evaluate the anticorrosive performance of these nanocomposite coatings: linear polarization resistance (LPR) and electrochemical impedance spectroscopy (EIS). Over the 56-day immersion of the cement mortar, EIS measurements were carried out periodically using the AUTOLAB PGSTAT 30 (Ecochemie, Netherlands). In the LPR test, the steel was polarized around its corrosion potential $(-30 \mathrm{mV}$ to 


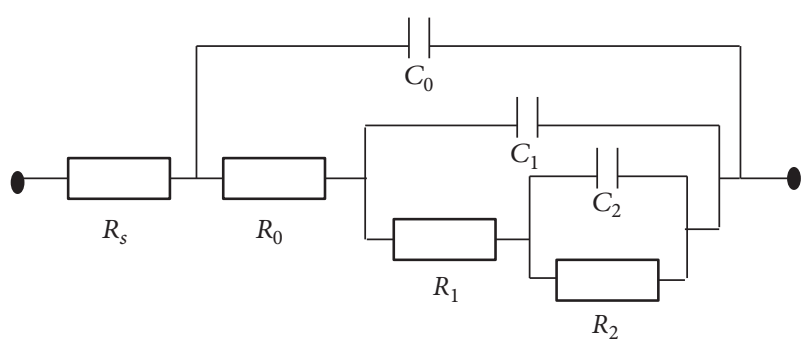

FIGURE 2: Schematic drawing of the equivalent circuit. $R_{s}$ is associated with the electrolyte resistance; $R_{0}$ and $C_{0}$ represent the electrical resistance and capacitance of the bulk mortar, respectively; $R_{1}$ and $C_{1}$ are the resistance and the capacitance of coating, respectively. $C_{2}$ is the capacitance of the double layer and $R_{2}$ is the charge transfer resistance at the steel/electrolyte interface.

$30 \mathrm{mV} / \mathrm{SCE}$ versus OCP) by a direct current (DC) signal at a scan rate of $0.2 \mathrm{mV} / \mathrm{s}$. Polarization resistance $\left(R_{p}\right)$ is defined by the slope of the potential versus current density plot at $0.2 \mathrm{mV} / \mathrm{s}$. Corrosion current $\left(I_{\text {corr }}\right)$ is calculated from $I_{\text {corr }}=$ $B / R_{p}$, assuming $B=26 \mathrm{mV}$ for the actively corroding rebar (uncoated steel embedded in concrete) [22].

The temperature of electrochemical tests is room temperature $\left(\right.$ at $\left.25^{\circ} \mathrm{C}\right)$. The waiting time is 10 minutes, as required to stabilize the system and the open circuit potentials for EIS measurements.

For EIS measurement, the steel rebar was polarized at $\pm 10 \mathrm{mV}$ around its open circuit potential (OCP) by an alternating current $(\mathrm{AC})$ signal with its frequency ranging from $100 \mathrm{kHz}$ to $100 \mathrm{mHz}$ (10 points per decade). In this research, the fitting of all EIS data was performed using a simple equivalent electric circuit (EEC) model (Figure 2) [20, 23]. These obtained data are the response of the equivalent circuit. In Figure 2, we divide the electrochemical system into three integrated interfaces, corresponding to three different time constants: electrolyte-bulk mortar interface, coatingelectrolyte interface, and steel-electrolyte interface. $R_{s}$ is the solution resistance between the reference electrode and the working electrode (steel rebar), which depends not only on the resistivity of the electrolyte (ionic concentration, type of ions, temperature, etc.) but also on the geometry of the area in which current is carried. The "electrolyte" in electrolytebulk mortar interface means the external solution of $\mathrm{NaOH}$, whereas $R_{0}$ and $C_{0}$ represent the electrical resistance and capacitance of the bulk mortar mix. $R_{1}$ and $C_{1}$ are the resistance and capacitance of coating characteristic of its pore network structure (the coating-electrolyte interface inside the coating). $R_{2}$ and $C_{2}$ are the charge transfer resistance of the steel and the double-layer capacitance on the steel surface (at the steel/electrolyte interface), respectively. If the coating was not intact, steel/electrolyte interface could be replaced by the coating/steel interface. For uncoated rebar sample, it should remove the $R_{1} C_{1}$ interface from the equivalent circuit.

Autolab software is used for fitting EIS data. Since the steel rebar (working electrode) is a corrodible electrode, the pure capacitance $(C)$ should be replaced by the constant phase element (CPE), with the exponent $\alpha$ less than 1 . When $\alpha$ is close to 1 , the $\mathrm{CPE}$ resembles a pure capacitor $(C)$. From the fitting results, $\alpha$ value varies from 0.6 to 1 .

\section{Results and Discussion}

3.1. Investigation by LPR Measurements. The corrosion current $\left(i_{\text {corr }}\right)$ and polarization resistance $\left(R_{p}\right)$ values of steel rebars were deduced from the measured LPR polarization curves. Figures 3 and 4 show the temporal evolution of polarization resistance and corrosion current of the rebars with and without epoxy coatings, during immersion for 56 days in $0.1 \mathrm{M} \mathrm{NaOH}$ solutions. For the $0.3 \mathrm{wt} . \%$ chloride samples, as shown in Figure 3(a), the incorporation of a small quantity of nanoparticles in the epoxy coating increased the polarization resistance of the epoxy-coated rebars, with the nano- $\mathrm{Fe}_{2} \mathrm{O}_{3}$ being the best. After 56 days of immersion, the presence of nanoparticles increased $R_{p}$ of epoxy-coated rebar 7.9 times for nano- $\mathrm{Fe}_{2} \mathrm{O}_{3}$ and 2.5 times for nanosilica. Regarding the corrosion current density (Figure 4(a)), the data indicated an active corrosion state of steel for the uncoated rebar $\left(i_{\text {corr }}>0.1 \mu \mathrm{A} / \mathrm{cm}^{2}\right)$ [23].

However, the steel rebar was well protected when it was coated by epoxy nano- $\mathrm{Fe}_{2} \mathrm{O}_{3}$ coating (likely to be passive with $i_{\text {corr }}<0.1 \mu \mathrm{A} / \mathrm{cm}^{2}$ ). Thus, in addition to enhancing the coating barrier performance, nano- $\mathrm{Fe}_{2} \mathrm{O}_{3}$ might also serve as an anodic-type corrosion inhibitor to significantly reduce the corrosion of the epoxy-coated steel [20]. An interesting observation from previous work [20] was that nanoparticles (nano- $\mathrm{SiO}_{2}$, nano- $\mathrm{Zn}$, nano- $\mathrm{Fe}_{2} \mathrm{O}_{3}$, and nanoclay) significantly also improved the corrosion resistance of coated steel in $\mathrm{NaCl}$ solution, with coating containing nano- $\mathrm{Fe}_{2} \mathrm{O}_{3}$ particles being the most effective. It was suggested that at least two possible mechanisms contributed to the enhanced corrosion protection of nanocomposite epoxy coatings. First, nanoparticles improved the quality of the cured epoxy coating, reduced the porosity of the coating matrix, and made the diffusion in zigzag path by deleterious species, leading to the improved barrier performance of the epoxy coating. Second, nanoparticles improved the adherence of the cured epoxy coating to the underlying substrate and altered the physiochemical properties of the coating-steel interface. With regard to the anticorrosive mechanism, the better adhesion strength of epoxy nano- $\mathrm{Fe}_{2} \mathrm{O}_{3}$ coating in this study confirmed the beneficial role of nanoparticles in mostly enhancing the chemical mechanism at metal/polymer interface, rather than the physical barrier effect of epoxy coating. Thus, the present findings suggest that the corrosion protection offered by the nanoparticles had more to do with modification of the coating-steel interface than with improvement in the coating pore network.

However, the scenario is different for the higher chloride concentration samples. As can be seen in Figures 3(b) and 4(b), the plain epoxy-coated steel exhibited the best protection against corrosion. The presence of nanoparticles in epoxy matrix reduced the $R_{p}$ values of epoxy-coated rebars, thus increasing their $i_{\text {corr }}$ values. A possible explanation might be attributed to the fact that chloride ions (and electrolyte) ingress into the coating over the time of immersion, and then rebar corrosion is initiated at the 


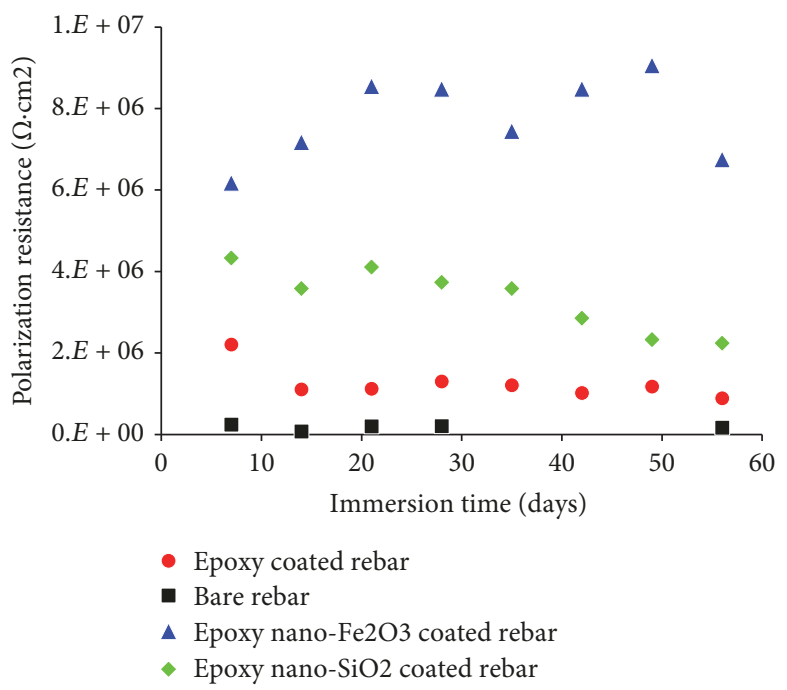

(a)

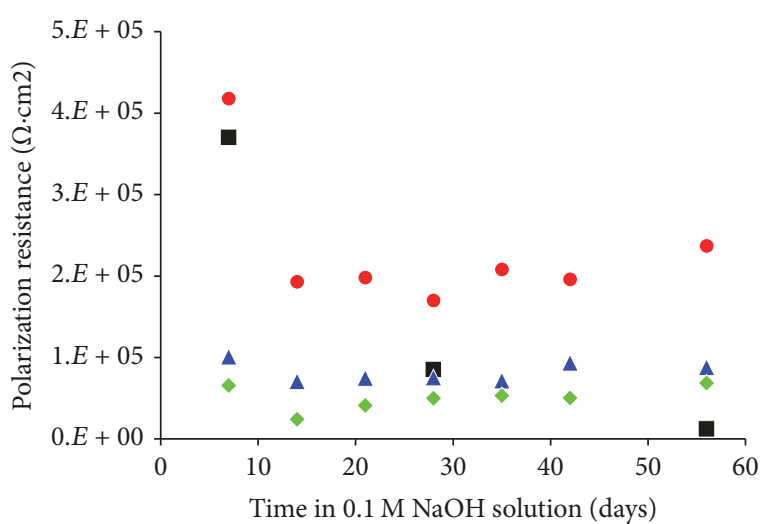

- Epoxy coated rebar

- Bare rebar

- Epoxy nano-Fe2O3 coated rebar

- Epoxy nano-SiO2 coated rebar

(b)

FIGURE 3: Temporal evolution of polarization resistance of steel rebar (with and without epoxy coatings) in a cement mortar in $0.1 \mathrm{M}$ NaOH solution: (a) $0.3 \mathrm{wt} . \%$ chloride cement mortar and (b) $0.5 \mathrm{wt} \%$ chloride cement mortar.

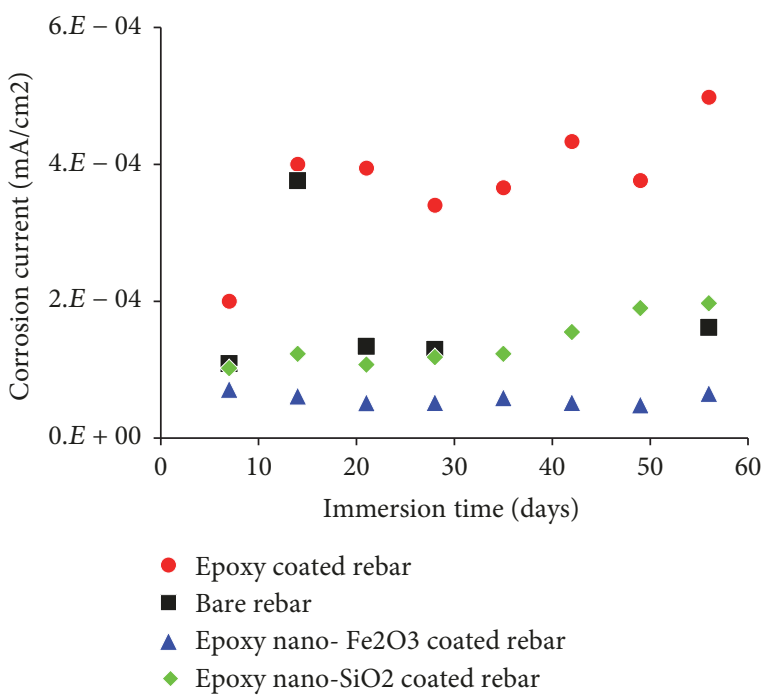

(a)

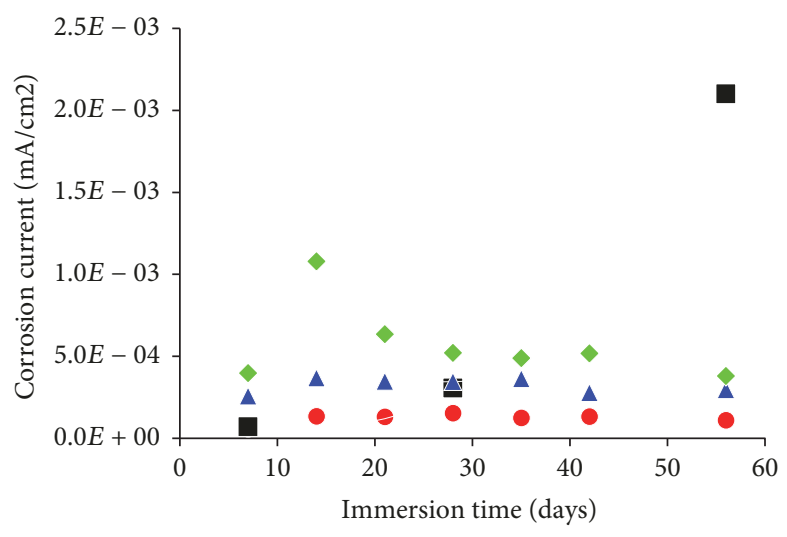

- Epoxy coated rebar
- Bare rebar
Epoxy nano- $\mathrm{Fe} 2 \mathrm{O} 3$ coated rebar
- Epoxy nano-SiO2 coated rebar

(b)

FIgURE 4: Temporal evolution of corrosion current of steel rebar (with and without epoxy coatings) in a cement mortar in $0.1 \mathrm{M} \mathrm{NaOH}$ solution: (a) $0.3 \mathrm{wt} . \%$ chloride cement mortar and (b) $0.5 \mathrm{wt} . \%$ chloride cement mortar.

epoxy/nanoparticles/rebar interface. To elucidate the effect of nanoparticles on the electrochemical interfaces of systems, EIS measurements were conducted.

3.2. Investigation by EIS Measurements. Figures 5 and 6 present the selected Nyquist diagrams of the bare steel and steel coated by various epoxy coatings in the contaminated mortars, during immersion time. For bare steel (without epoxy coatings), as shown in Figures 5(a) and 6(a), the Nyquist diagrams featured the diffusion straight lines, which might be attributed to the porous mortar-rebar interface. At high frequencies, the spectra presented an electrical resistance for the ionic conduction in the electrolyte filling the mortar pores. The semicircles at intermediate frequencies could not be observed on Nyquist diagrams for bare rebar in salt-contaminated mortar. Thus, the corrosion condition was not severe with this chloride level $(0.3 \%$ and $0.5 \%$ by weight of cement, resp.). The open circuit potential (OCP) measurements for these rebars provided qualitative information on the corrosion condition, indicating the probability of it occurring. For the $0.3 \%$ chloride mortars (Figure $7(\mathrm{a})$ ), during immersion for 28 days, the OCP values oscillated from $-204 \mathrm{mV}$ to $-246 \mathrm{mV} / \mathrm{SCE}$ which, according to ASTM C876 standard, still corresponds to an intermediate risk of corrosion. However, for the $0.5 \%$ chloride mortars (Figure $7(\mathrm{~b})$ ), from the 21st day of immersion, the OCP values oscillated 


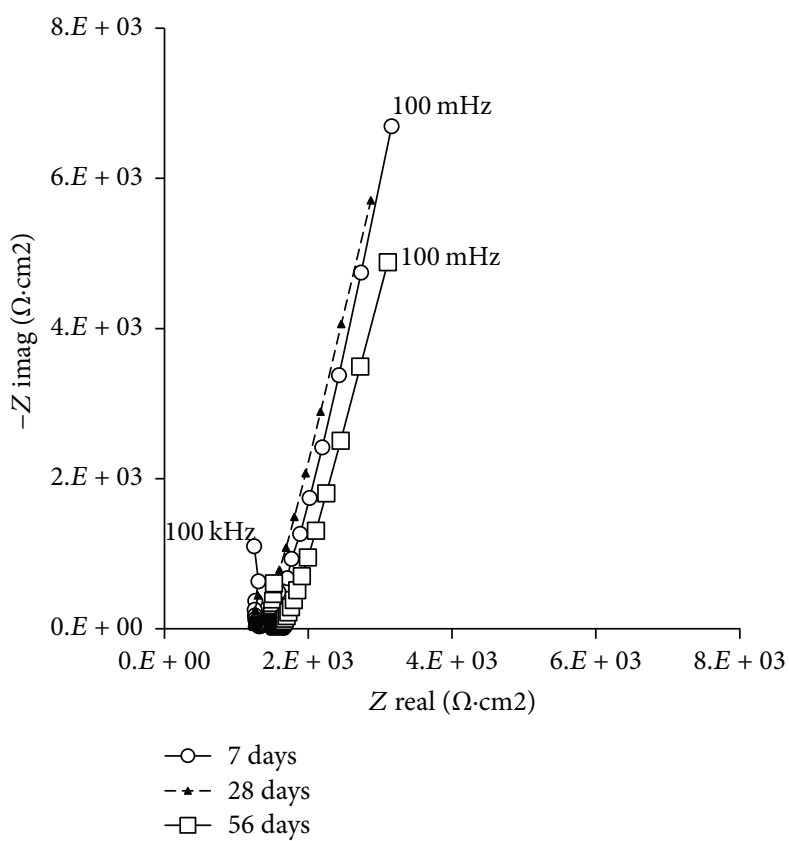

(a)

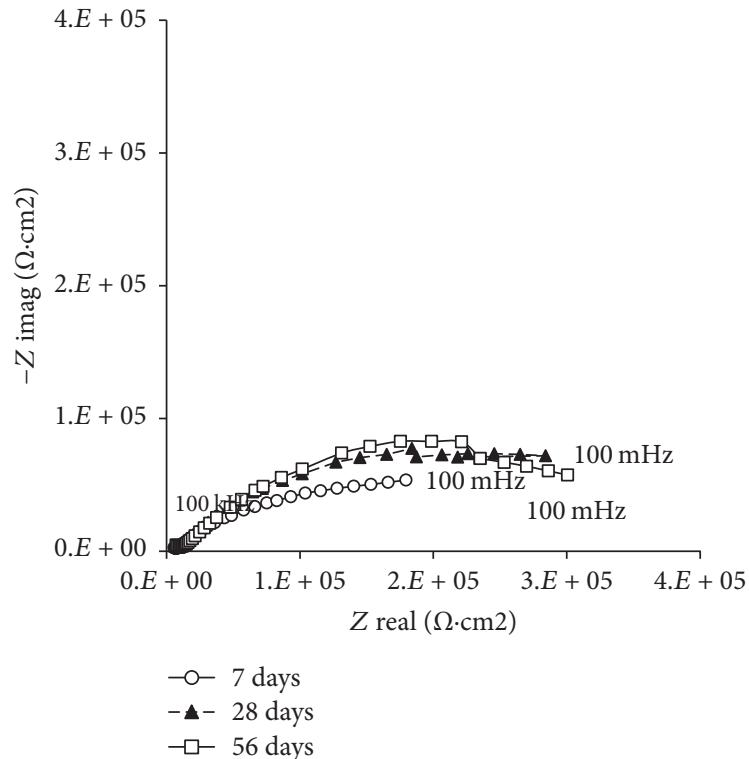

(c)

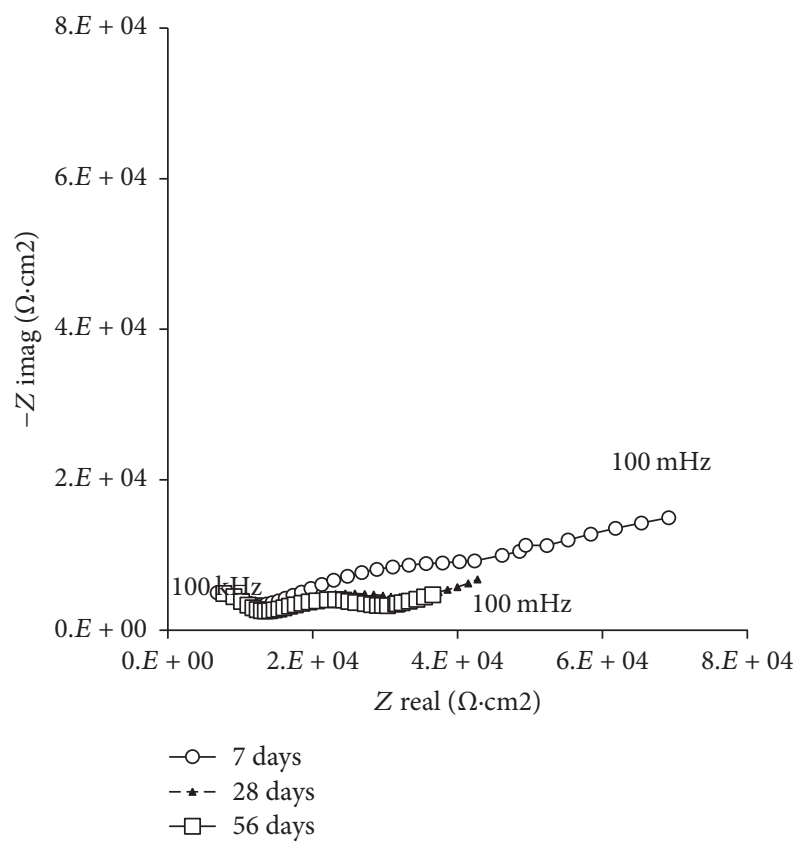

(b)

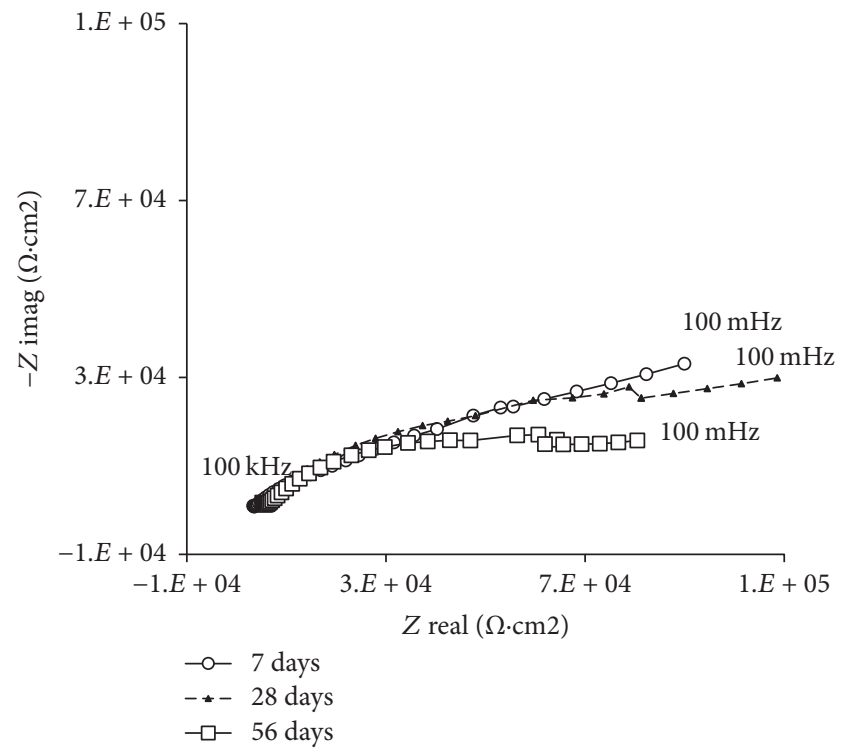

(d)

FiguRE 5: EIS Nyquist diagram evolution for steel rebars of cement mortar ( $0.3 \mathrm{wt} . \%$ chloride) during immersion for $105 \mathrm{days}$ in $0.1 \mathrm{M} \mathrm{NaOH}$ solution: (a) without epoxy coating, (b) with epoxy coating, (c) with nano- $\mathrm{Fe}_{2} \mathrm{O}_{3}$ modified epoxy coating, and (d) with nano-SiO $\mathrm{O}_{2}$ modified epoxy coating.

from $-328 \mathrm{mV}$ to $-391 \mathrm{mV} / \mathrm{SCE}$, which corresponds to the active corrosion of rebar.

For epoxy-coated rebar, as observed in Figures 5(b)-5(d) and 6(b)-6(d), the Nyquist diagrams derived from the EIS measurements featured capacitive loops, corresponding to the electrochemical interfaces. The fitting of all EIS data was then performed using a simple equivalent electric circuit (EEC) model (presented in Figure 2). The obtained EEC parameters are given in Tables 1 and 2.
3.2.1. The Steel-Electrolyte Interface. The capacitance values $\mathrm{C}_{2}$ obtained for uncoated rebar were in range of $0.7-0.8 \mu \mathrm{Fcm}^{-2}$ during 56 days of salt ponding (Table 1). This order of magnitude is similar to data reported for the electrochemical double-layer capacitance of steel in $\mathrm{NaCl}$ solution $\left(0.4 \mu \mathrm{Fcm}^{-2}\right)$ [24]. This data indicated that steel rebar came into contact directly with the electrolyte in the pore solution of cement mortar, resulting in active corrosion ( $i_{\text {corr }}>0.1 \mu \mathrm{A} / \mathrm{cm}^{2}$, Figure 4$)$. It should be noted that the 


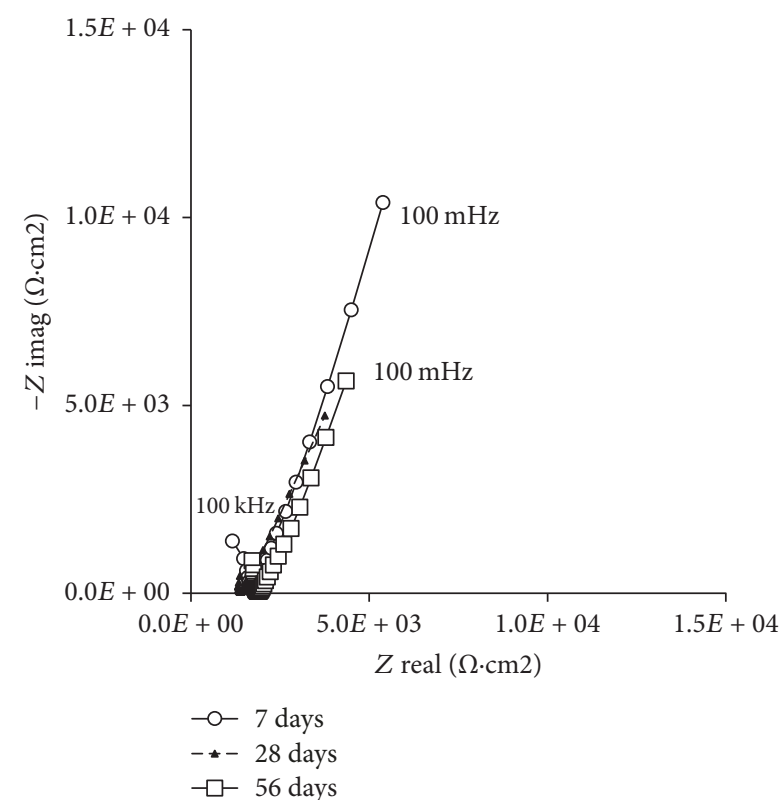

(a)

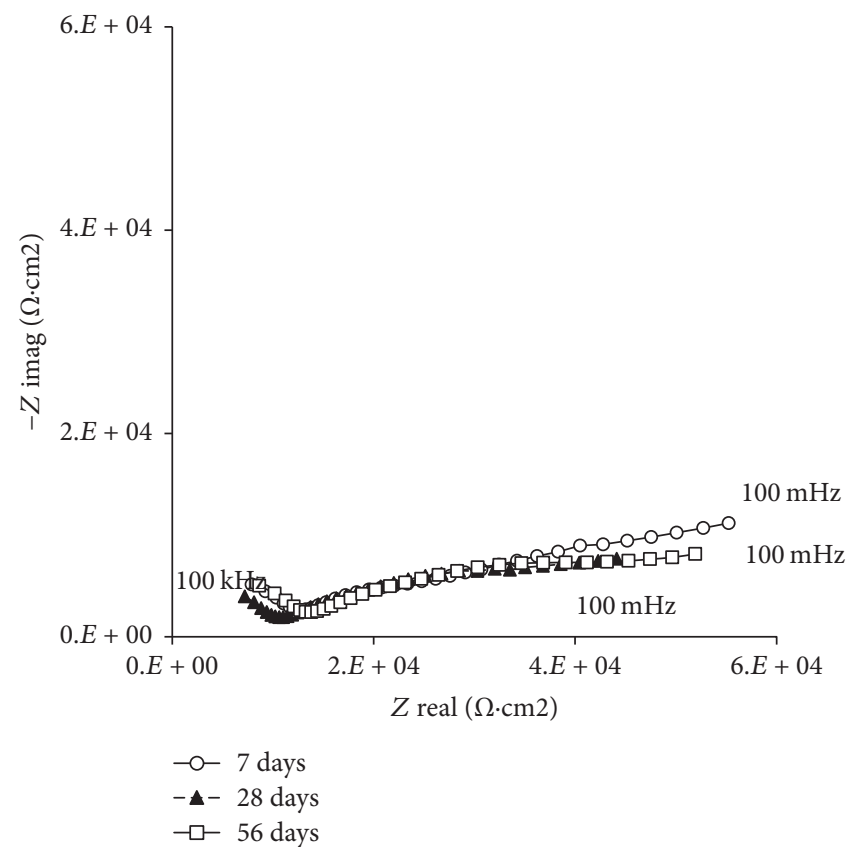

(c)

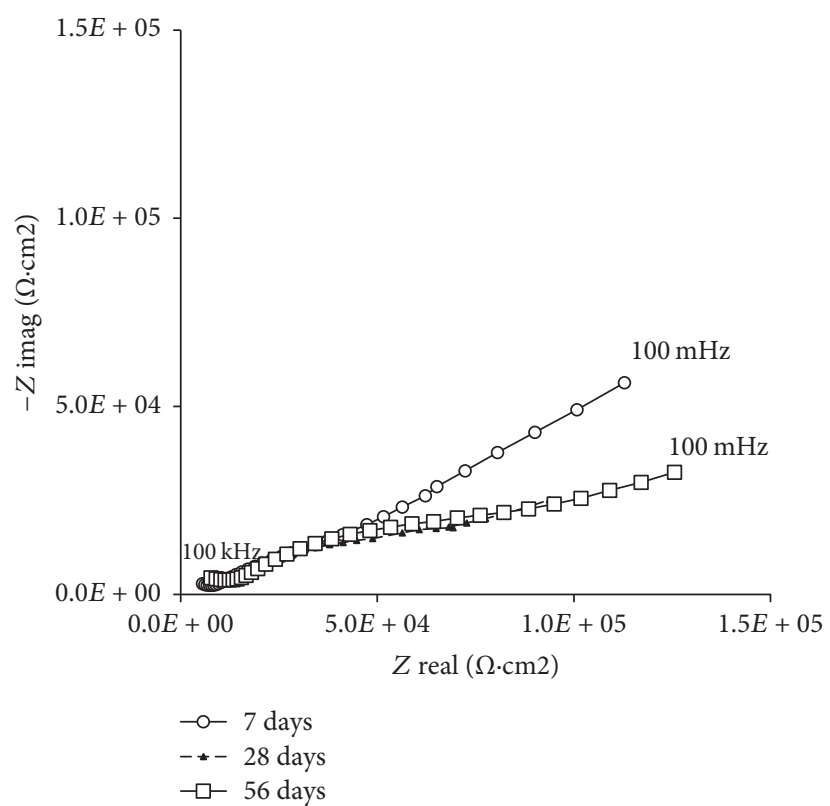

(b)

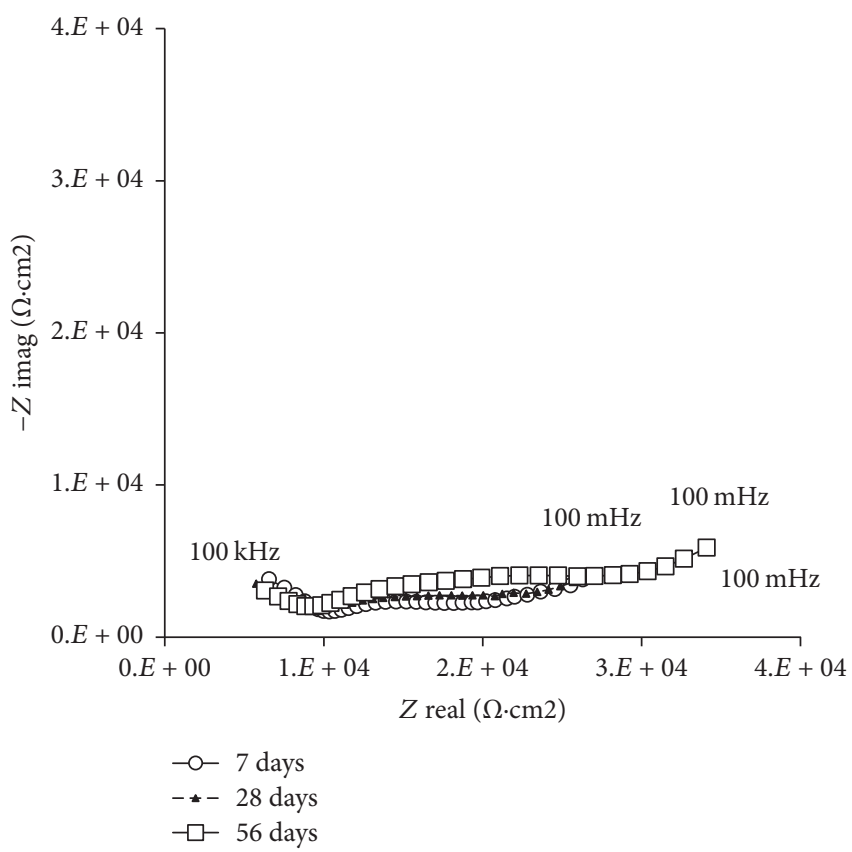

(d)

FIGURE 6: EIS Nyquist diagram evolution for steel rebars of cement mortar ( $0.5 \mathrm{wt} . \%$ chloride) during immersion for $105 \mathrm{days}$ in $0.1 \mathrm{M} \mathrm{NaOH}$ solution: (a) without epoxy coating, (b) with epoxy coating, (c) with nano- $\mathrm{Fe}_{2} \mathrm{O}_{3}$ modified epoxy coating, and (d) with nano-SiO 2 modified epoxy coating.

charge transfer resistances $R_{2}$ obtained by fitting EIS were slightly lower than the polarization resistances $R_{p}$ measured by potentiodynamic polarization curves. A possible explanation is that surface area for steel-electrolyte interface, where steel was directly in contact with electrolyte, was lower than the whole surface area of steel rebar.

However, the capacitance values $C_{2}$ obtained for other epoxy-coated rebars (including the nanocomposite coating) were much lower than that obtained for the uncoated rebar (e.g., $10^{-12}-10^{-14} \mathrm{Fcm}^{-2}$ ). This order of magnitude was similar to the $C_{1}$ capacitance of the epoxy coating. Data obtained from the polarization measurements showed that steel rebar was likely to be passive when it is coated by epoxy nanocomposite coatings. Thus, for the coated rebar, the steel/electrolyte interface should be replaced by the coating/steel interface. Then, $R_{2}$ and $C_{2}$ were the electrical 


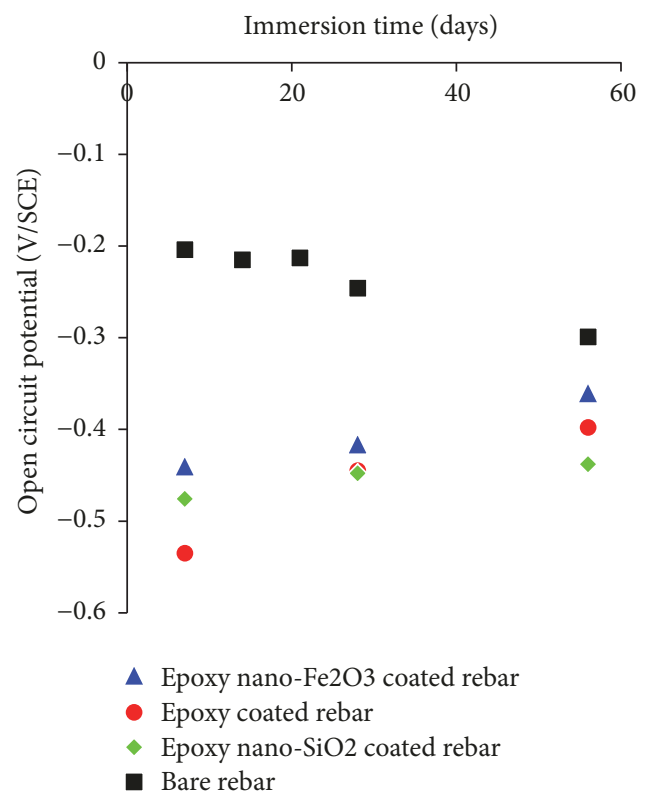

(a)

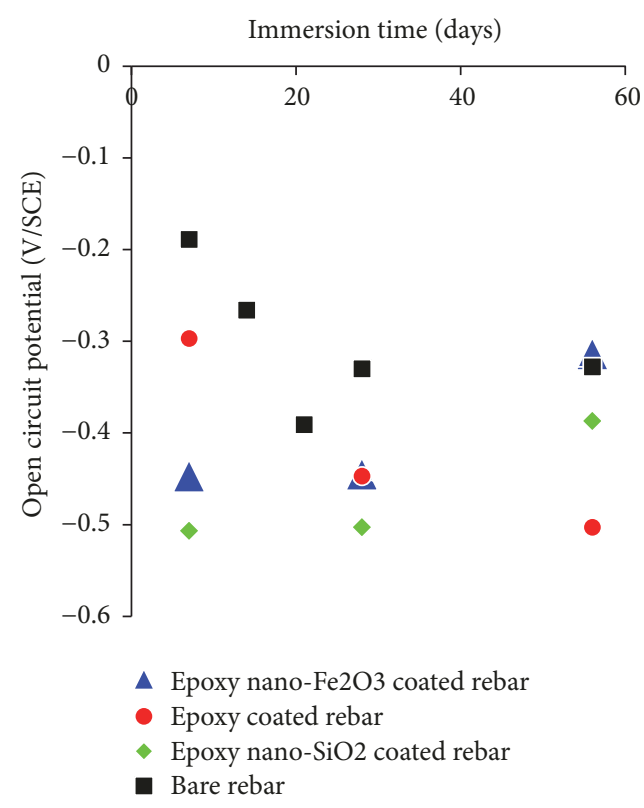

(b)

FIGURE 7: OCP evolution of steel reinforced mortar samples immersed in a $0.1 \mathrm{M} \mathrm{NaOH}$ solution: (a) 0.3 wt.\% chloride cement mortar and (b) $0.5 \mathrm{wt} \%$ chloride cement mortar.

TABLE 1: Parameters of equivalent circuits for the uncoated and coated neat resin rebar in different chloride cement mortars ( 0.3 and 0.5 wt.\%) after 7, 28, and 56 days in $0.1 \mathrm{M} \mathrm{NaOH}$ solution.

\begin{tabular}{|c|c|c|c|c|c|c|c|}
\hline Time of ponding (days) & $R_{s}(\Omega)$ & $R_{0}(\mathrm{k} \Omega)$ & $C_{0}(\mathrm{~F})$ & $R_{1}(\mathrm{M} \Omega)$ & $C_{1}(\mathrm{~F})$ & $R_{2}(\mathrm{k} \Omega)$ & $C_{2}(\mathrm{~F})$ \\
\hline \multicolumn{8}{|c|}{ Uncoated, 0.3 wt. $\%$ chloride cement mortar } \\
\hline 7 & 108.7 & 139.7 & $1 E-14$ & & & 100.0 & $9.01 E-04$ \\
\hline 28 & 103.7 & 47.7 & $1 E-14$ & & & 95.5 & $9.99 E-04$ \\
\hline 56 & 128.7 & 76.3 & $1 E-14$ & & & 99.8 & $8.51 E-04$ \\
\hline \multicolumn{8}{|c|}{ Uncoated, 0.5 wt. $\%$ chloride cement mortar } \\
\hline 7 & 136.7 & 200.0 & $1.00 E-14$ & & & 100.0 & $1.76 E-04$ \\
\hline 28 & 113.6 & 43.4 & $1.00 E-14$ & & & 43.4 & $2.73 E-04$ \\
\hline 56 & 152.8 & 100.0 & $1.00 E-14$ & & & 100.0 & $2.68 E-04$ \\
\hline \multicolumn{8}{|c|}{ Coated with neat resin, $0.3 \mathrm{wt}$ \% chloride cement mortar } \\
\hline 7 & 348 & 10.65 & $6.38 E-09$ & 22.63 & $1 E-14$ & 185.6 & $1 E-14$ \\
\hline 28 & 384 & 3.08 & $7.21 E-09$ & 42.2 & $2.87 E-14$ & 12.09 & $1.1 E-09$ \\
\hline 56 & 402 & 4.12 & $4.34 E-11$ & 60.3 & $1.8 E-10$ & 3.32 & $2.11 E-10$ \\
\hline \multicolumn{8}{|c|}{ Coated with neat resin, 0.5 wt. $\%$ chloride cement mortar } \\
\hline 7 & 224.2 & 32.6 & $5.5 E-09$ & 133 & $2.43 E-13$ & 93.8 & $1 E-14$ \\
\hline 28 & 221.8 & 15.88 & $3 E-09$ & 18.39 & $4 E-10$ & 20.69 & $1 E-14$ \\
\hline 56 & 256.5 & 15.71 & $2 E-09$ & 67.7 & $1.68 E-09$ & 22.90 & $1 E-14$ \\
\hline
\end{tabular}

resistance and capacitance of the interface layer between steel rebar and coating, respectively.

For the 0.3 wt. $\%$ chloride mortars, as shown in Tables 1 and 2, the incorporation of nanoparticle into the epoxy coating increased the steel/coating's resistance $R_{2}$, indicating improved adhesion strength. However, for the $0.5 \mathrm{wt} . \%$ chloride mortars, the incorporation of nanoparticle into the epoxy coating reduced the steel/coating's resistance $R_{2}$ (Tables 1 and 2), indicating the delamination underneath.
3.2.2. The Coating-Electrolyte Interface. Figure 8 shows the $R_{1}$ (epoxy coating resistance) values' evolution by function of nanoparticles. For $0.3 \mathrm{wt} . \%$ chloride mortars, as can be seen in Figure 8(a), the incorporation of a small amount of nanoparticles into the epoxy coating greatly increased the coating resistance $R_{1}$ by more than 1000 times, indicating reduced coating porosity and improved barrier performance for corrosion protection of the steel rebar. 
TABLE 2: Parameters of equivalent circuits for the epoxy/nanoparticles coated rebar in different chloride cement mortars (0.3 and 0.5 wt.\%) after 7, 28, and 56 days in $0.1 \mathrm{M} \mathrm{NaOH}$ solution.

\begin{tabular}{|c|c|c|c|c|c|c|c|}
\hline Time of ponding (days) & $R_{s}(\Omega)$ & $R_{0}(\mathrm{k} \Omega)$ & $C_{0}(\mathrm{~F})$ & $R_{1}(\mathrm{M} \Omega)$ & $C_{1}(\mathrm{~F})$ & $R_{2}(\mathrm{k} \Omega)$ & $C_{2}(\mathrm{~F})$ \\
\hline \multicolumn{8}{|c|}{ Coated with epoxy/nano- $\mathrm{SiO}_{2}, 0.3$ wt.\% chloride cement mortar } \\
\hline 7 & 148.6 & 11.65 & $5 E-10$ & 103.1 & $8 E-13$ & 197.9 & $6 E-13$ \\
\hline 28 & 197.6 & 15.69 & $9.5 E-11$ & 11.14 & $1.5 E-10$ & 26.82 & $1 E-14$ \\
\hline 56 & 237.9 & 16.11 & $3.4 E-11$ & 39.6 & $3.4 E-11$ & 11.46 & $5.76 E-10$ \\
\hline \multicolumn{8}{|c|}{ Coated with epoxy $/$ nano- $\mathrm{SiO}_{2}, 0.5$ wt. $\%$ chloride cement mortar } \\
\hline 7 & 268.8 & 3.91 & $2 E-09$ & 4.25 & $4.15 E-09$ & 4.51 & $1.88 E-14$ \\
\hline 28 & 252.1 & 4.29 & $3 E-09$ & 4.71 & $5.15 E-09$ & 5.03 & $2.25 E-14$ \\
\hline 56 & 250.4 & 6.55 & $2.66 E-09$ & 7.43 & $3.79 E-09$ & 8.16 & $1 E-14$ \\
\hline \multicolumn{8}{|c|}{ Coated with epoxy/nano- $\mathrm{Fe}_{2} \mathrm{O}_{3}, 0.3$ wt.\% chloride cement mortar } \\
\hline 7 & 305 & 23.2 & $5 E-10$ & 421 & $8 E-13$ & 210.9 & $6 E-13$ \\
\hline 28 & 276.3 & 30.6 & $8.69 E-11$ & 153.3 & $9 E-12$ & 164.2 & $4.67 E-11$ \\
\hline 56 & 344 & 53.5 & $6.63 E-10$ & 88.1 & $5.73 E-10$ & 49.7 & $2.25 E-11$ \\
\hline \multicolumn{8}{|c|}{ Coated with epoxy/nano- $\mathrm{Fe}_{2} \mathrm{O}_{3}, 0.5$ wt. $\%$ chloride cement mortar } \\
\hline 7 & 280.1 & 11.56 & $1.71 E-09$ & 11.56 & $1.68 E-09$ & 11.56 & $1 E-14$ \\
\hline 28 & 274.5 & 10.96 & $1.53 E-09$ & 10.96 & $2.81 E-09$ & 10.96 & $1.16 E-14$ \\
\hline 56 & 391 & 12.90 & $2.92 E-09$ & 12.90 & $2.92 E-09$ & 12.90 & $1 E-14$ \\
\hline
\end{tabular}

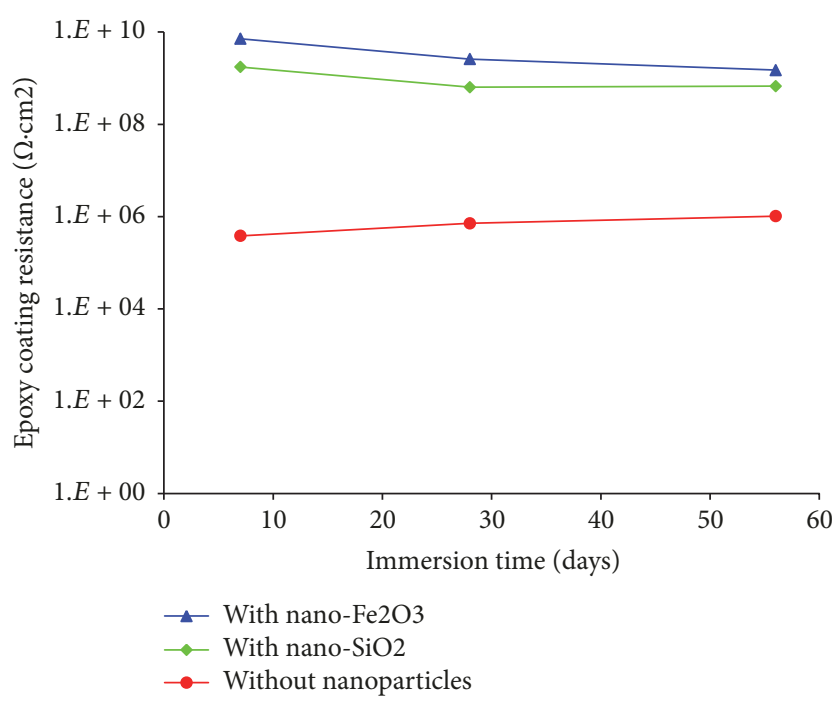

(a)

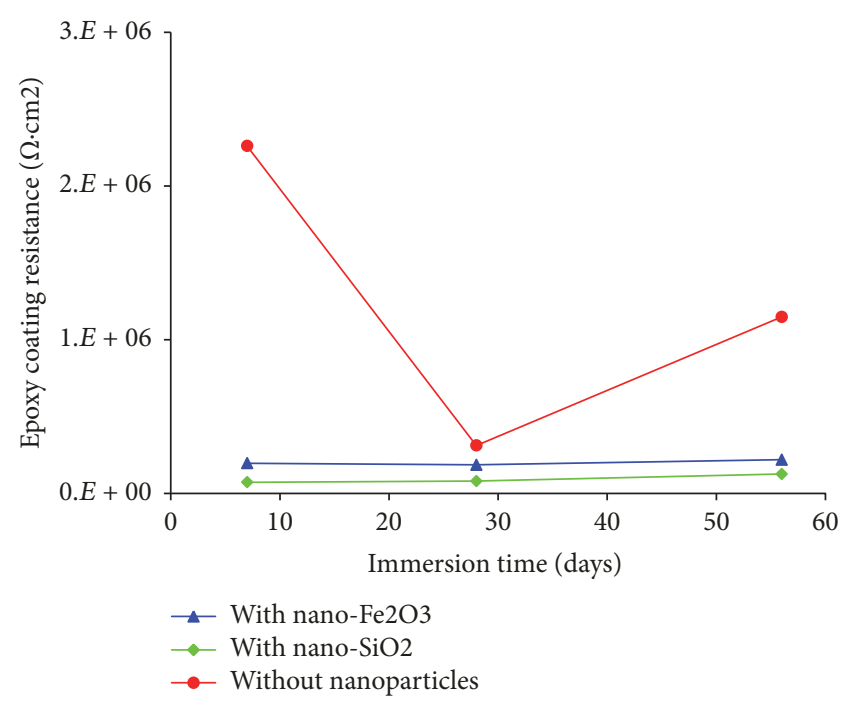

(b)

Figure 8: Epoxy coating resistance evolution by function of nanoparticles: (a) 0.3 wt.\% chloride cement mortar and (b) 0.5 wt. $\%$ chloride cement mortar.

Regarding the effect of nanoparticles on the morphology of epoxy coating, it was reported by TEM images in [21] that epoxy/nano- $\mathrm{SiO}_{2}$ coating showed less agglomeration than the epoxy/nano- $\mathrm{Fe}_{2} \mathrm{O}_{3}$ coating (due to its higher specific surface area). Appropriate dispersion of the nanofiller in epoxy resin is very significant to take advantage of nanoscale reinforcement and to improve the barrier effect of coating. The high value of coating resistance $R_{1}$ for epoxy/nano$\mathrm{SiO}_{2}$ coating might also suggest that the corrosion protection offered by the $\mathrm{SiO}_{2}$ nanoparticles had more to do with the improvement in the coating pore network than any modification of the coating-steel interface. The $\mathrm{SiO}_{2}$ nanoparticles tend to occupy free spaces in the epoxy coating and serve to bridge more molecules in the interconnected matrix, leading to increased cross-linking density of the cured epoxy as well as improved corrosion protection for the steel substrate [20]. However, in case of $0.5 \mathrm{wt} . \%$ chloride mortars, the presence of nanoparticles in epoxy matrix reduced their coating resistance $R_{1}$. It could be also seen that, over the time of immersion in the $\mathrm{NaOH}$ solution, the values of $R_{1}$ decreased and $C_{1}$ increased, indicating the entry of electrolyte into the epoxy coatings $[25,26]$.

3.2.3. The Electrolyte-Bulk Mortar Interface. In the Nyquist diagrams, the high frequency data can be attributed to the properties of the electrolyte-bulk mortar interface, with $R_{0}$ 
and $C_{0}$ representing the electrical resistance and capacitance of the bulk mortar mix. These two parameters have very important practical implications as they can affect the rate of steel corrosion propagation in concrete, the efficiency of electrochemical rehabilitation of reinforced concrete, and the electrical properties of concrete in general.

In general, over the time of immersion in the electrolytes, $R_{0}$ decreased, indicating the entry of electrolyte into the cement mortar. As shown in Tables 1 and 2, over the 56 days of salt ponding, the evolution of $R_{0}$ and $C_{0}$ over time and their differences between samples can be accounted for by the ever-changing pore fluid chemistry, the continued cement hydration with active participation of chloride, and corrosion product's propagation in mortar.

The high value of $R_{0}$ for uncoated rebar might be related to the corrosion product's propagation in mortar under the active corrosion of rebar. The average capacitance value $C_{0}$ obtained from all samples was in range of $0.03-0.8 \mathrm{nFcm}^{2}$ during the 56 days of salt ponding. This order of magnitude is much lower than data reported for bulk concrete $\left(1-10 \mathrm{mFcm}^{2}\right.$ ) [27] but was comparable to data reported for bulk mortar $\left(0.8-1 \mathrm{nFcm}^{2}\right)[23,28]$.

\section{Conclusions}

Epoxy modified with nanoparticles which was coated on steel rebar embedded in the chloride contaminated cement mortar has been investigated. $\mathrm{NaCl}$ was added to a fresh Portland cement paste (at $0.3 \%$ and $0.5 \%$ by weight of cement) to simulate the chloride contamination at the critical level. When the chloride concentration in cement mortar was $0.3 \mathrm{wt} . \%$, the electrochemical monitoring of the coated rebar in cement mortar over 56 days of immersion in $0.1 \mathrm{M}$ $\mathrm{NaOH}$ solutions suggested the beneficial role of nanoparticles in significantly improving the corrosion resistance of the coated steel in cement mortar, with the nano- $\mathrm{Fe}_{2} \mathrm{O}_{3}$ particles being the most effective. The LPR test revealed that, after 56 days of immersion, the nanoparticles reduced the corrosion current of steel rebar by 2.5-7.9 times. The EIS measurements indicated that the incorporation of nanoparticles increased the coating resistance. In addition to enhancing the coating barrier performance, at least one other mechanism was at work to account for the role of the nanoparticles in improving the anticorrosive performance of these epoxy coatings. When the chloride concentration in cement mortar was $0.5 \mathrm{wt} . \%$, incorporation of nanoparticles into the epoxy matrix did not enhance the corrosion resistance of epoxy coating for the rebars. At this critical level, chloride ions had initiated the rebar corrosion through nanoparticles at the epoxy/rebar interface.

\section{Conflicts of Interest}

The authors declare that there are no conflicts of interest regarding the publication of this paper.

\section{References}

[1] F. Pacheco Torgal, S. Miraldo, J. A. Labrincha, and J. De Brito, "An overview on concrete carbonation in the context of eco-efficient construction: Evaluation, use of SCMs and/or RAC," Construction and Building Materials, vol. 36, pp. 141-150, 2012.

[2] X. Shi, T. A. Nguyen, P. Kumar, and Y. Liu, "A phenomenological model for the chloride threshold of pitting corrosion of steel in simulated concrete pore solutions," Anti-Corrosion Methods and Materials, vol. 58, no. 4, pp. 179-189, 2011.

[3] C. L. Page, N. R. Short, and W. R. Holden, "The influence of different cements on chloride-induced corrosion of reinforcing steel," Cement and Concrete Research, vol. 16, no. 1, pp. 79-86, 1986.

[4] G. K. Glass and N. R. Buenfeld, "Chloride-induced corrosion of steel in concrete," ProgStrucEng Mater, vol. 2, pp. 448-458, 2000.

[5] F. Galliano and D. Landolt, "Evaluation of corrosion protection properties of additives for waterborne epoxy coatings on steel," Progress in Organic Coatings, vol. 44, no. 3, pp. 217-225, 2002.

[6] A. Talo, O. Forsen, and S. Ylasaari, "Corrosion protective polyaniline epoxy blend coatings on mild steel," Synthetic Metals, vol. 102, no. 1-3, pp. 1394-1395, 1999.

[7] V. B. Miskovic-Stankovic, M. R. Stanic, and D. M. Drazic, "Corrosion protection of aluminium by a cataphoretic epoxy coating," Progress in Organic Coatings, vol. 36, pp. 53-63, 1999.

[8] B. Wetzel, F. Haupert, and M. Q. Zhang, "Epoxy nanocomposites with high mechanical and tribological performance," Composites Science and Technology, vol. 63, no. 14, pp. 20552067, 2003.

[9] M. Q. Zhang, M. Z. Rong, S. L. Yu, B. Wetzel, and K. Friedrich, "Improvement of tribological performance of epoxy by the addition of irradiation grafted nano-inorganic particles," Macromolecular Materials and Engineering, vol. 287, p. 111, 2002.

[10] S. Yamini and R. J. Young, "Stability of crack propagation in epoxy resins," Polymer Journal, vol. 18, no. 10, pp. 1075-1080, 1977.

[11] C. K. Lam and K. T. Lau, "Localized elastic modulus distribution of nanoclay/epoxy composites by using nanoindentation," Composite Structures, vol. 75, no. 1-4, pp. 553-558, 2006.

[12] G. Shi, M. Q. Zhang, M. Z. Rong, B. Wetzel, and K. Friedrich, "Friction and wear of low nanometer Si3N4 filled epoxy composites," Wear, vol. 254, no. 7-8, pp. 784-796, 2003.

[13] A. Hartwig, M. Sebald, D. Pütz, and L. Aberle, "Preparation, characterisation and properties of nanocomposites based on epoxy resins - An overview," Macromolecular Symposia, vol. 221, pp. 127-135, 2005.

[14] F. Dietsche, Y. Thomann, R. Thomann, and R. Mülhaupt, "Translucent acrylic nanocomposites containing anisotropic laminated nanoparticles derived from intercalated layered silicates," Journal of Applied Polymer Science, vol. 75, no. 3, pp. 396405, 2000.

[15] L. H. Yang, F. C. Liu, and E. H. Han, "Effects of P/B on the properties of anticorrosive coatings with different particle size," Progress in Organic Coatings, vol. 53, no. 2, pp. 91-98, 2005.

[16] S. V. Lamaka, M. L. Zheludkevich, K. A. Yasakau, R. Serra, S. K. Poznyak, and M. G. S. Ferreira, "Nanoporous titania interlayer as reservoir of corrosion inhibitors for coatings with self-healing ability," Progress in Organic Coatings, vol. 58, no. 23, pp. 127-135, 2007.

[17] O. Becker, R. Varley, and G. Simon, "Morphology, thermal relaxations and mechanical properties of layered silicate nanocomposites based upon high-functionality epoxy resins," Polymer Journal, vol. 43, no. 16, pp. 4365-4373, 2002. 
[18] E. Huttunen-Saarivirta, G. V. Vaganov, V. E. Yudin, and J. Vuorinen, "Characterization and corrosion protection properties of epoxy powder coatings containing nanoclays," Progress in Organic Coatings, vol. 76, no. 4, pp. 757-767, 2013.

[19] N. Wang, K. Cheng, H. Wu, C. Wang, Q. Wang, and F. Wang, "Effect of nano-sized mesoporous silica MCM-41 and MMT on corrosion properties of epoxy coating," Progress in Organic Coatings, vol. 75, no. 4, pp. 386-391, 2012.

[20] X. Shi, T. A. Nguyen, Z. Suo, Y. Liu, and R. Avci, "Effect of nanoparticles on the anticorrosion and mechanical properties of epoxy coating," Surface \& Coatings Technology, vol. 204, no. 3, pp. 237-245, 2009.

[21] T. A. Nguyen, H. Nguyen, T. V. Nguyen, H. Thai, and X. Shi, "Effect of nanoparticles on the thermal and mechanical properties of epoxy coatings," Journal of Nanoscience and Nanotechnology, vol. 16, no. 9, pp. 9874-9881, 2016.

[22] J. A. Gonzalez and C. Andrade, "Eftect of carbonation, chlorides and relative ambient humidity on the corrosion of galvanized rebarsembedded in concrete," British Corrosion Journal, vol. 17, no. 1, pp. 21-28, 1982.

[23] T. Anh Nguyen and X. Shi, "A mechanistic study of corrosion inhibiting admixtures," Anti-Corrosion Methods and Materials, vol. 56, no. 1, pp. 3-12, 2009.

[24] N. Scromeda and TJ. Katsube, "Electrochemical double-layer capacitance of metals, including some precious metals: preliminary results," in Geological Survey of Canada, Current Research (Online), Natural Resources Canada, Canada, North America, 2008.

[25] V. B. Miskovic-Stankovic, D. M. Drazic, and M. J. Teodorovic, "Electrolyte penetration through epoxy coatings electrodeposited on steel," Corrosion Science, vol. 37, no. 2, pp. 241-252, 1995.

[26] V. B. Miskovic-Stankovic, D. M. Dražić, and Z. KačarevićPopović, "The sorption characteristics of epoxy coatings electrodeposited on steel during exposure to different corrosive agents," Corrosion Science, vol. 38, no. 9, pp. 1513-1523, 1996.

[27] L. Dhouibi, E. Triki, and A. Raharinaivo, "The application of electrochemical impedance spectroscopy to determine the long-term effectiveness of corrosion inhibitors for steel in concrete," Cement and Concrete Composites, vol. 24, no. 1, pp. 35-43, 2002.

[28] X. He and X. Shi, "Chloride permeability and microstructure of Portland cement mortars incorporating nanomaterials," Transportation Research Record, vol. 2070, no. 1, pp. 13-21, 2008. 

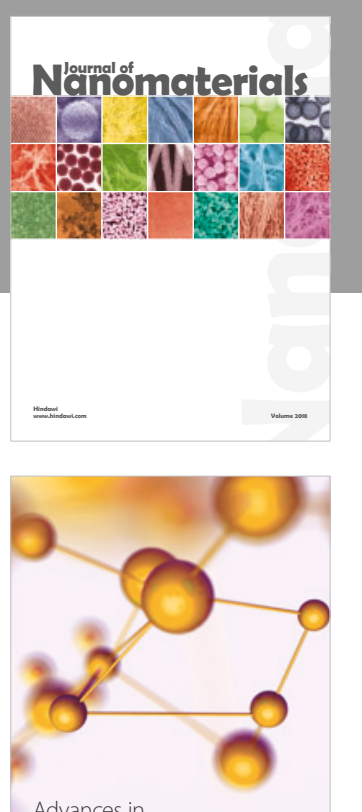

Physical Chemistry
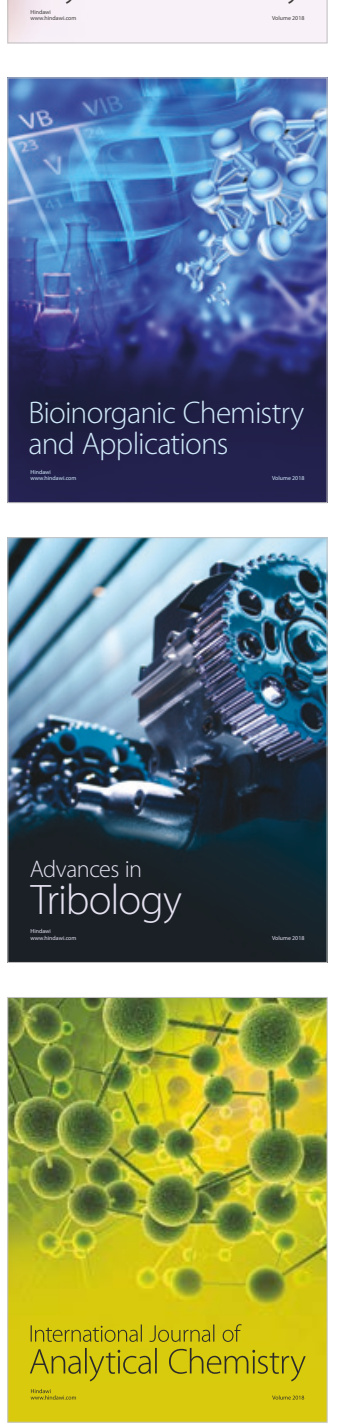

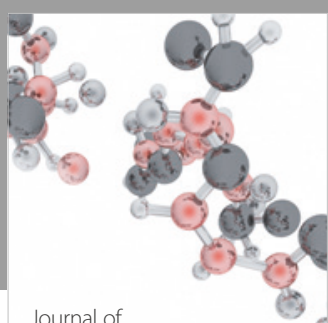

Analytical Methods

in Chemistry

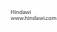

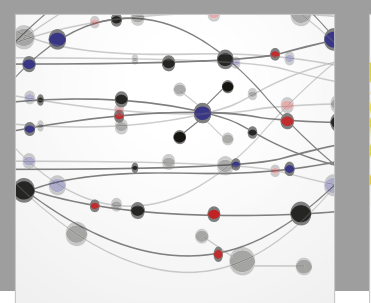

The Scientific World Journal

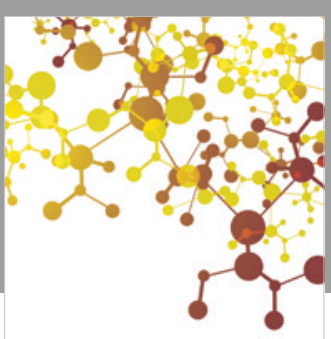

Journal of

Applied Chemistry
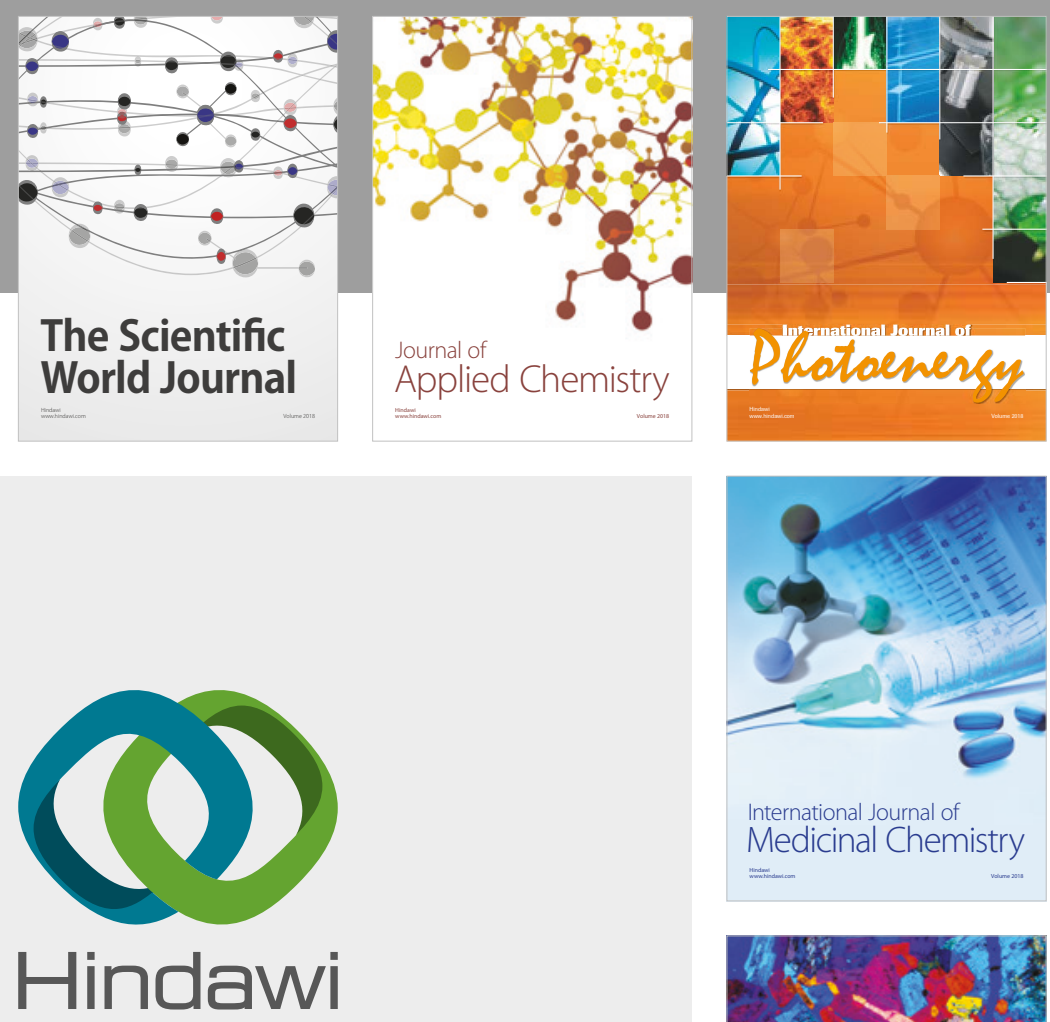

Submit your manuscripts at

www.hindawi.com
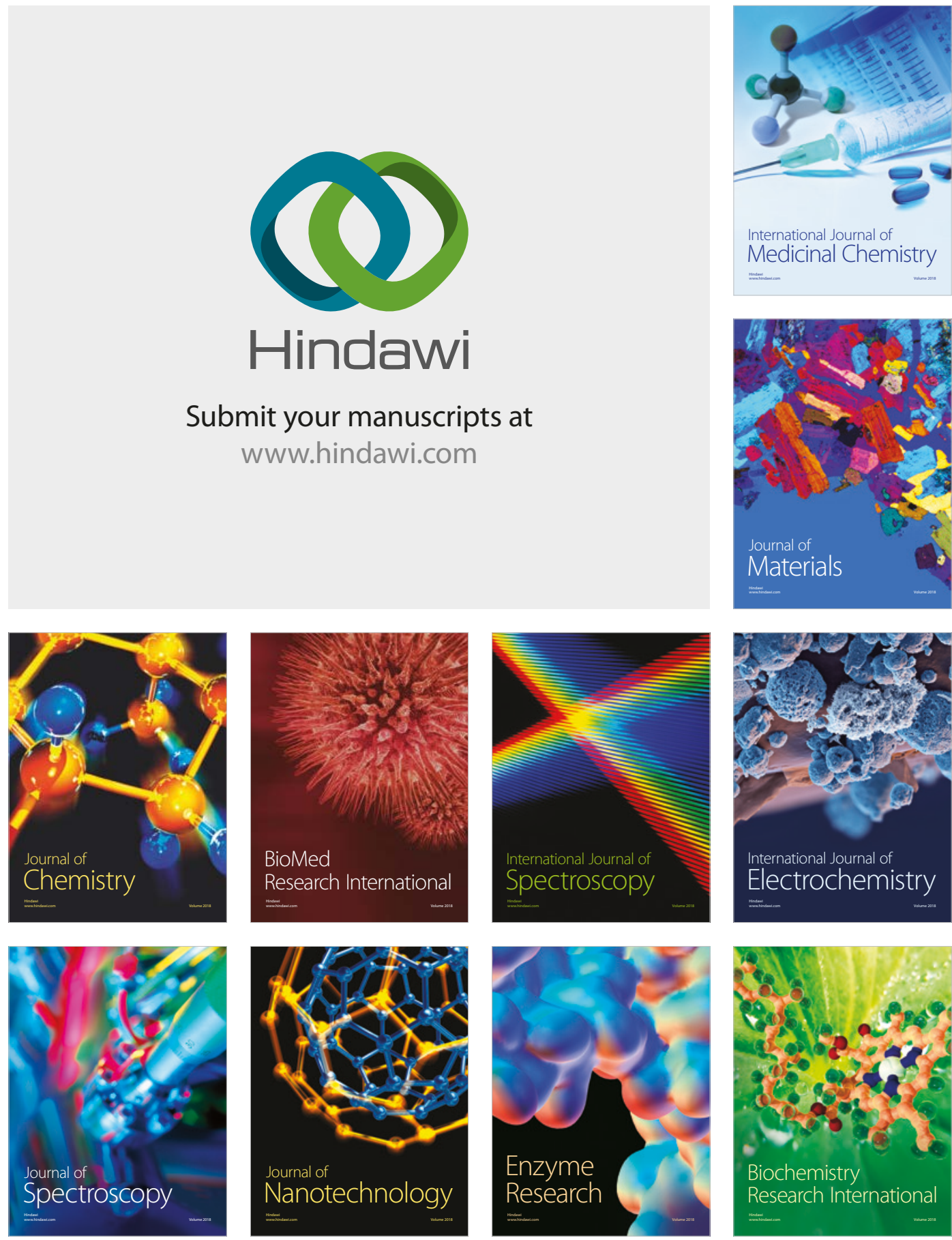
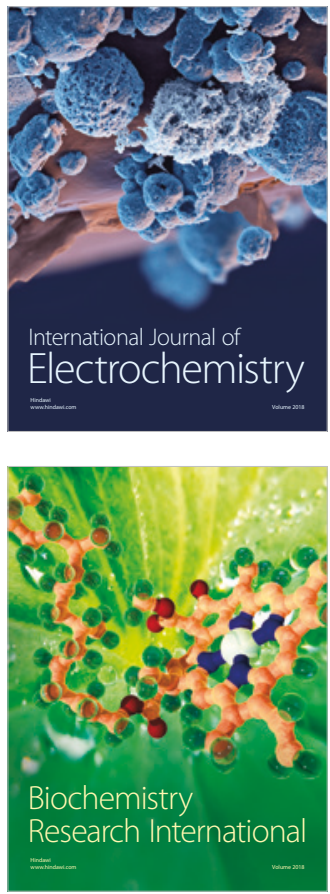